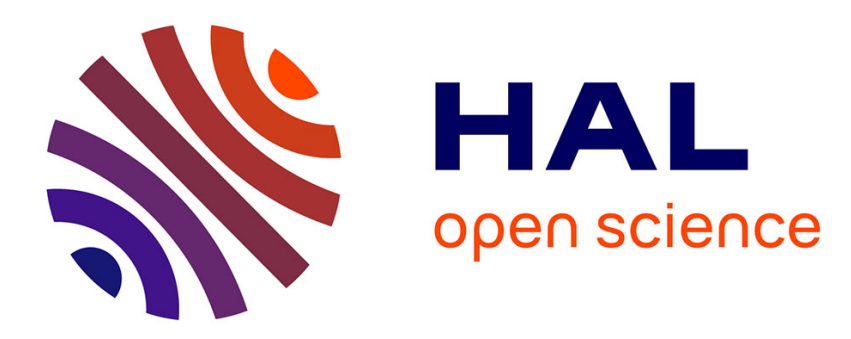

\title{
INTERACTIONS OF SWIFT H, H+2 AND H+3 WITH THIN FOILS
}

\author{
M.J. Gaillard
}

\section{To cite this version:}

M.J. Gaillard. INTERACTIONS OF SWIFT H, $\mathrm{H}+2$ AND $\mathrm{H}+3$ WITH THIN FOILS. International Conference On Beam-Foil Spectroscopy 5, 1978, Lyon, France. pp.C1-342-C1-349, 10.1051/jphyscol:1979174 . jpa-00218454

\section{HAL Id: jpa-00218454 https://hal.science/jpa-00218454}

Submitted on 1 Jan 1979

HAL is a multi-disciplinary open access archive for the deposit and dissemination of scientific research documents, whether they are published or not. The documents may come from teaching and research institutions in France or abroad, or from public or private research centers.
L'archive ouverte pluridisciplinaire HAL, est destinée au dépôt et à la diffusion de documents scientifiques de niveau recherche, publiés ou non, émanant des établissements d'enseignement et de recherche français ou étrangers, des laboratoires publics ou privés. 
INTERACTIONS OF SWIFT $\mathrm{H}, \mathrm{H}_{2}^{+}$AND $\mathrm{H}_{3}^{+}$WITH THIN FOILS

M. J. Gaillard

Institut de Physique Nucléaire (and IN2P3), Université Claude Bernard Lyon-1 43, Bd du 11 Novembre 1918 - 69621 Villeurbanne, France

Résumé - L'interaction de faisceaux rapides $(\sim \mathrm{MeV})$ de $\mathrm{H}_{3} \mathrm{H}_{2}^{+}$et $\mathrm{H}_{3}^{+}$avec des cibles minces présente quelques aspects spécifiques. Nous décrivons d'abord des effets dynamiques apparaissant lorsque l'on utilise des faisceaux moléculaires : les ions se déplaçant à grande vitesse pouvant être accompagnés d'une fluctuation périodique de la densité électronique du milieu, les fluctuations créées par les constituants d'un ion moléculaire pourront interférer, perturbant ainsi leur propagation dans le solide. Nous montrons ensuite que 1'utilisation de faisceaux neutres ou moléculaires permet de mettre en évidence le rôle des électrons du projectile ou de la cible dans la formation d'atomes neutres. Nous présentons ensuite les mécanismes envisagés pour expliquer la présence d'ions moléculaires en sortie de cibles minces et nous montrons enfin comment l'observation de l'explosion de projectiles moléculaires peut être mise à profit pour déterminer leur structure.

Abstract - Some specific effects seen in the interactions of swift hydrogenic beams penetrating thin foils are presented. We describe first dynamic effects due to periodic electron density fluctuations trailing fast charged particles moving in solids which can sustain plasmon oscillations. Studies of non equilibrated charge distribution dows tream very thim foils permit us to separate the role played by projectile and target electrons in neutral atom production. The observation of bound molecules emerging from thin target raisesquestions about their formation and the processes involved. Finally we show how original measurements on the dissociation of fast molecular ions by thin foils has opened up new possibilities for the investigation of molecular ion structure

\section{INTRODUCTION}

Recently, considerable interest has centered on the penetration of fast molecularions through solids since it has been demonstrated that the propagation of spatially correlated ions through matter is influenced by the electronic polarization wake trailing each ion [1].

This paper present some features which have been observed when $\mathrm{MeV}$ atomic and molecular hydrogen ions penetrate thin foils. We areinterested in the interactions occuring inside the solid and in phenomena which involve correlated electrons and ions emerging in a close vicinage from the foils.

The first part is a survey of some anomalies observed with molecular beams which can be attributed to polarization wake effects. In the second part, we comment on non-equilibrated neutral fractions measured dowstream very thin foils and related processes pertaining to the existence of mo- molecular states at emergence. The observation of bound molecular ions dowstream foils is then discussed in terms of electron capture and wake effects. Finally we show that the study of the dissociation of fast molecularions opens up new possibilities for the investigations of molecular structure.

\section{POLARIZATION - WAVE EFFECTS}

Evidences of the electronic-polarization wake were first seen through the observation of energy and angular distributions of break-up fragments emerging from thin amorphous or crystalline targets bombarded with $\mathrm{H}_{2}^{+}, \mathrm{H}_{3}^{+}$and $\mathrm{HeH}^{+}$molecular targets ions of $\mathrm{MeV}$ energy range [1]. The ion velocity $v$ being larger than the Bohr velocity $v_{0}$ the binding electrons are believed to be stripped within a few $\AA$ of the solid. This a consequence of the large cross-section for electron loss due to collisions with target electrons. Then the 
charged components arising from the molecular ion repel each other due to the Coulomb force and the cluster begins to explode. With thin targets, the internuclear distances remain smaller than the screening length $a=v / \omega_{p}$, where $\omega_{p}$ is the voIume plasma frequency of the target. The Coulomb repulsion initiated in the foil will be generally completed in vacuum dowstream the foil, and will result in a small isotropic component added to the initial ion velocities. Consequently, the effects of the Coulomb explosion can be seen in the angular and energy distributions of ions detected after emergence. Of course, the distributions depends on the population of vibrational levels of the incident molecular ions [2]. Moreover, multiple scattering, slowing down and straggling due to electronic interactions modify this simple description.

Earlier results obtained by Golovchenko and Laegsgaard [3] were consistent with the Coulomb explosion model. They measured the distributions for protons transmitted through a $100 \AA$ thick carbon foil bombarded with $2 \mathrm{MeV} \mathrm{H}_{2}^{+}$ions. With such a thin foil, most of the repulsion occurs after the foil.

Further experiments performed wi th thicker targets exhibited particular features, and a new force was necessary to explain them and other new effects observed with molecular beams. This force is related to the existence of a polarization wake trailing ions moving in solids.

The concept of electronic polarization wake was predicted in 1955 by R. Ritchie in his thesis and published with Neufeld in 1955 [4]. Some years ago, Neelavathi, Ritchie and Brandt [5] studied the possibility for an electron to be trapped in the wake created by a moving ion. They expected surf-riding electrons to appear as a group of electrons with velocity centered about $v$, the velocity of the ion.

When a fast charged particle is moving faster than the Fermi velocity in solid which can sustain well defined plasmon oscillations, the electrons of the solid react in an effort to screen the ion charge and an oscillatory charge density which is stationnary in the projectile frame trails the ion like a wake behind a ship. This polarization wake sets up a potential in the medium. The resulting force acts as a brake on the projectile itself and is responsible for the electronic stopping power of the solid.

To probe this potential, it was tempting to use molecular projectiles with internuclear distances $(\sim 1 \mathrm{~A})$ short enough to allow vicinage effects through interference between the wakes trailing behind each partner. The first observations concerned an alignment effect in the motion of ion clusters moving through solids [1]. In one of them, we mea sured the energy spectra of protons emerging in the beam direction from amorphous carbon foils bombarded with $2 \mathrm{MeV} \mathrm{FI}_{3}^{+}$and $\mathrm{HeH}^{+}$beams (figure 1). As predicted by the Coulomb explosion model, two peaks were observed corresponding to the leading and trailing particles. The low energy peak corresponding to trailing ions is higher than the high ener gy peak and the explanation is that the trailing ions feel an additionnal force - the so-called wake force - which attract it towards the leading ion track. Thus the wake force enhances the emergence of trailing ions at $0^{\circ}$ and gives rise to the asymmetry observed.

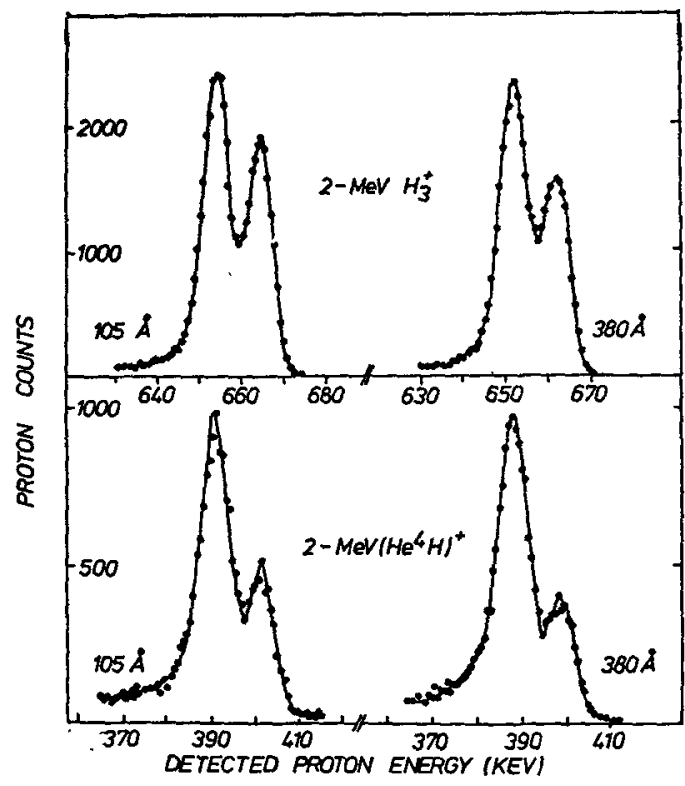

Figure 1

These kind of measurements have been extended at Argonne with a large variery of molecular 
ions [6]. As an example, figure 2 shows the experimental joint distributions in energy and angle for protons emerging from a $85 \AA$ carbon foil bombarded by a $2 \mathrm{MeV} \mathrm{HeH}^{+}$beam. The simple C.E. model would give a flat or uniform ring. In fact, two peaks appear. The higher intensity peak correspond to trailing particles which have felt the weak force due to the leading ion, while the lower peak corresponding to the leading ions is a consequence of the alignment of the internuclear axis of the cluster. On the right side, the calculated results come from a computer simulation of the experiment under the assumption that the $\alpha$-particle and proton motions are influenced by direct Coulomb explosion and wake-force. The good agreement with experimental results indicates the validity of the wake-model.

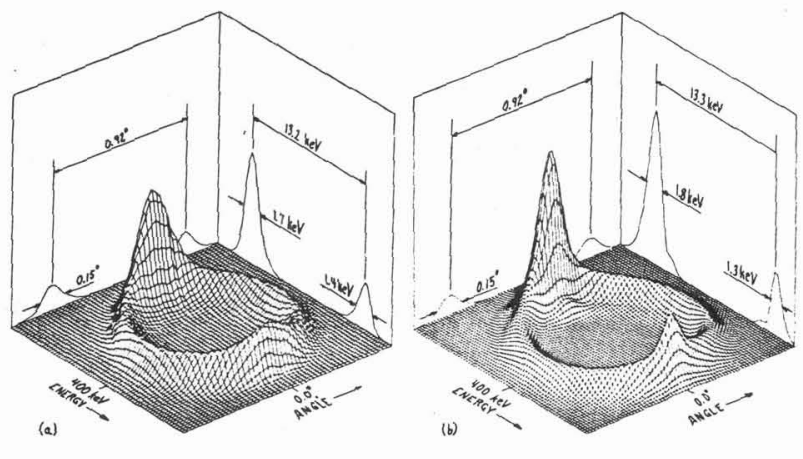

Figure 2

Other experimental consequences of vicinage effects in solids have been seen, one of these is in the excess of energy loss suffered by the ion cluster considered as a whole. For isolated ions, the total electronic stopping power is due in part to close collisions resulting from single electron-ion collisions and in part to distant collisions resulting from resonant excitation of the medium. For $\mathrm{MeV}$ molecular ions, the mean internuclear distances are such that, in regard to close collisions, the partnexs can be considered as independent particles, but in regard to distant collisions, the cluster acts as a whole. Assuming an equipartition of energy loss into close and distant collisions one can predict that, for very short dwell time, the energy loss per proton should be 1.5 for $\mathrm{H}_{2}^{+}$beam and 2.0 for $\mathrm{H}_{3}^{+}$beam if we take 1.0 for protons of same velocity.

First measurements of the excess of energy loss were reported by Dettmann et al. [7] for $270 \mathrm{keV} \mathrm{H} \mathrm{H}_{2}^{+}$ions bombarding a $500 \mathrm{~A}$ thick carbon foil. Figure 3 shows a summary of measurements performed by Brandt et al. [8] in which the square of the effective charge number per proton representing the excess of energy loss is plotted vs. the dwell time in various foils bombarded with $\mathrm{H}_{2}^{+}$and $\mathrm{H}_{3}^{+}$molecular ions. We can see that for small dwelltime, protons, moving as part of a spatially correlated cluster have an effective charge number greater than unity. These values remain lower than the expected values even for smallest dwell-time for which vicinage effects should be important.

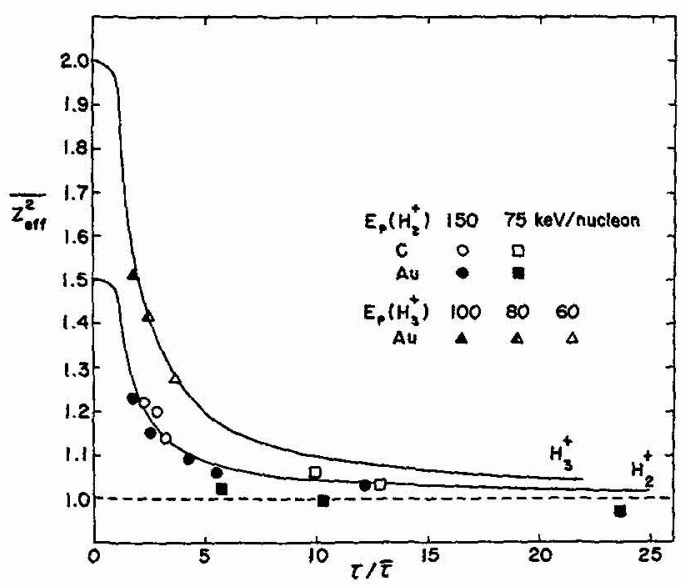

Figure 3

These measurements have been extended

[9] to higher velocity in order to reach shorter dwell-time. The energy loss per proton in clusters was only 1.2 times that observed for proton beam of same velocity. Similar measurements performed with $\mathrm{O}_{2}^{-}$beams with energies of 2.9 to 2.0 $\mathrm{MeV}$ per atom showed similar results. These results are in good agreement with estimations using the partition rule of Lindhard and Winther.

The vicinage effect has been interpreted by Brandt et al. [ 8$]$ in terms of interferences between wakes generated by the correlated moving ions. They point out that such stopping power 
measurements of light clusters would permit the test of the partition rule of stopping power and to determine the fraction of target electrons which participate into the collective excitation. However recent calculations using Lindhard's dielectric function [10], had questioned the existence of a general relation between the partition rules for the energy loss of a single ion and the energy loss of a cluster of ions with internuclear distances brackedted between the two characteristic distances $r_{\text {close }}$ and $r$ distant

A particular aspect of the alteration of the stopping power has been studied by Mc Corkle and Iafrate [11]. They show that greatly enhanced stopping power - several orders of magnitude for electrons and ions of very high energy moving in plasma can result from the interaction of sufficiently dense charged particle beams with matter. This beam density effect relies on a phase mixing of the polarization wakes produced by dense beam particles.

Berry et al. [12] have reported optical observation on the dissociation of fast molecules in thin foil. They measured the Doppler broadening produced in light emitted from the hydrogen atom emerging from a thin foil bombarded with hydrogenic molecular ions such as $\left(\mathrm{OH}_{2}\right)^{+},\left(\mathrm{OH}_{3}\right)^{+}$and $\left(\mathrm{NH}_{3}\right)^{+}$. Except for the $\mathrm{NH}_{3}^{+}$case, the Doppler profile is shifted to red wavelengths, i. e. towards lower velocity, a result similar to the energy measurement on the $\left(\mathrm{HeH}^{+}\right), \mathrm{H}_{2}^{+}$and $\mathrm{H}_{3}^{+}[1]$. They interpret these asymmetries in terms of polarization wake produced in the solid by the heavy component of the molecular ion.

Search for cluster effect in X-rays production have also been performed. Chen et al. [13] have reported on the measurements of Al $\mathrm{KX}$ rays yields with proton clusters in the energy range 90-150 $\mathrm{keV} / \mathrm{amu}$. The yields per proton for $\mathrm{H}_{2}^{+}$and $\mathrm{H}_{3}^{+}$were $4 \%$ and $8 \%$ smaller, respectively, than with a $\mathrm{H}^{+}$ beam of same velocity. However, these effects were accounted for quantitatively by the strongly enhanced stopping power of $\mathrm{Al}$ for ions moving in tight clusters. A. Lurio et al. [14] measured X-rays arising from ionization of target electrons with equal velocity $\mathrm{H}^{+}$ and $\mathrm{H}_{2}^{+}$projectiles in the $300-1200 \mathrm{keV} / \mathrm{amu}$ energy range. To within the experimental uncertainty of $\sim 1 \%$ no difference in yield were detected.

\section{NON-EQUILIBRA TED NEUTRAL FRAC TIONS}

A very useful consequence of ion and molecular ion-foils interactions pertains to the distribution of charge states in the ion beam emerging from the foils. Most of the early charge exchange information obtained correspond to equilibrium charge states. We have been mainly concerned with the non-equilibrated neutral fraction and have used hydrogenic beams for initial measurements. An important aspect of this problem is the description of a projectile charge state inside the solid in the context of electron capture and loss cross sections. Brandt considers these cross sections to be due to the gain and loss of correlation in speed and direction between the projectile and electrons. This can be investigated experimentally by studying nonequilibrated charge distributions, a method which was employed for instance by Datz et al. [15] for channeled oxygen ions in gold crystals. In our velocity range and with the thinnest foils of carbon available, it was possible to observe such non equilibrated distributions with incident neutral atom $H$ and with molecular ion beams [16].

Figure 4 shows neutral fraction $\Phi_{0}$ emerging from carbon foils bombarded with 1.2 to 2.4 $\mathrm{MeV}$ neutral atoms $\mathrm{H}$, as a function of the dwelltime spent by the projectiles inside the foils. For very short dwell-time the increase of $\Phi_{0}$ is compatible with the extrapolation to zero thickness that $\Phi_{0}$ approaches unity when the dwell-time approaches zero. The characteristic time of the exponential decrease permits one to calculate the experimental projectile electron los s cross-section $\sigma_{\text {loss }}$. For larger dwell-time the $\Phi_{0}$ curves reach the equilibrated values $\Phi_{0}(\infty)$ which are the same as those obtained with proton beams having the same velocity. From these $\Phi_{0}(\infty)$, we can extract the experimental capture cross section $\sigma_{\text {capt }}$. The mean free path before loss of 
correlation between the projectile electron and the proton as deduced from $\sigma$ loss is found to be longer than that for inelastic collision of a free electron injected into the solid with the same velocity, indicating that an electron correlated with a moving proton in a solid has a probability of decorrelation by scattering which is lower than that of an isolated electron [16]: The main difficulty here is the exact description of the proton-electron system moving through a solid in a state of correlation. We note that the existence of a bound state in a solid has been considered recently [17].

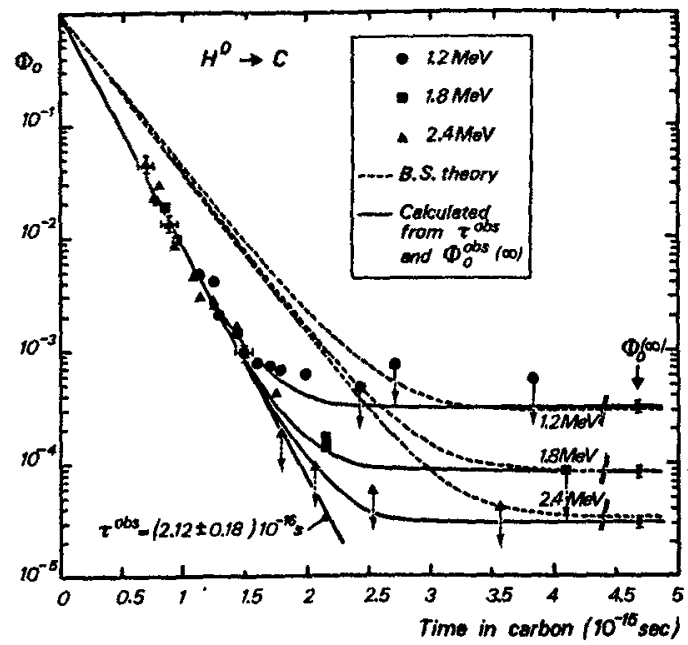

Figure 4

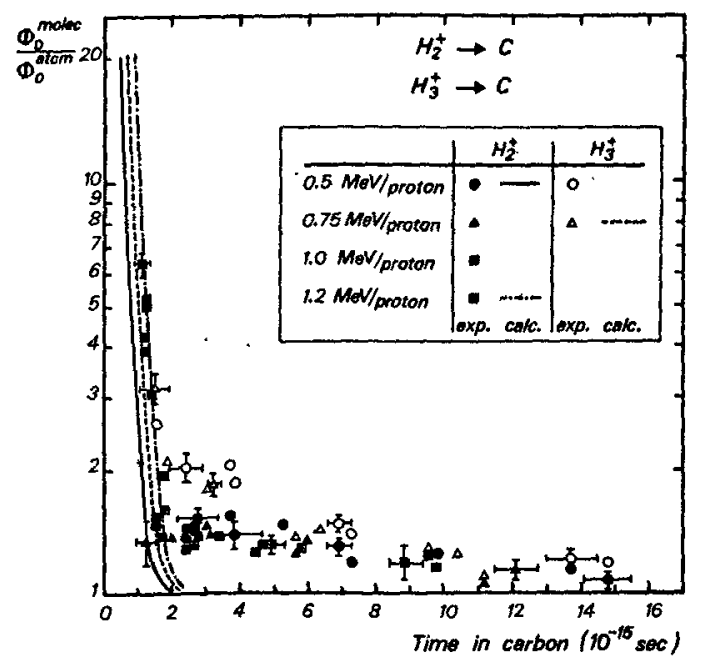

Figure 5

Non-equilibrated neutral fractions have also been measured with $\mathrm{H}_{2}^{+}$and $\mathrm{H}_{3}^{+}$molecular ion beams [18]. Figure 5 shows first that proton cluster produce more neutrals per incident proton than isolated protons of same velocity, as previously reported by Meggitt et al. [19]. In addition, we observe a non-equilibrium effect for two different regimes : for long dwell-time, a slow increase of the over production of neutrals, while for short dwell time, an exponential increase.

We analyse the short dwell-time effect corresponding to the electron transmission regime by assuming that an $\mathrm{H}_{2}^{+}$molecule penetrating matter is equivalent to two independent projectiles, one proton and one neutral atom, without collective effects between the projectiles in the cluster. A similar picture is assumed for $\mathrm{H}_{3}^{+}$projectiles (one proton and two neutral atoms). Three results of such calculations axe plotted on this figure for comparison with experimental data. We can conclude that the role played by the projectile electrons is confirmed and that they have essentially the same probability for losing their correlation with moving protons when they are injected as atomic electrons or as molecular electrons.

In contrast the analysis for long dwelltime reveals a cluster effect outside the solid which takes place just after emergence from the foil. A target electron having gained correlation with a proton and which is not captured by it at emergence has a supplementary probability to be captured by another proton of the same cluster to form a neutral atom. This collective effect clearly depends on the distance separating the protons in a cluster as it emerges from the foil.

In order to study more completely electron capture processes involving projectile or target electrons we measured angular and energy distributions of protons and neutrals emerging from thin carbon foils bombarded with $\mathrm{H}_{2}^{+}$and $\mathrm{H}_{3}^{+}$be ams of same velocity. With very thin foils, the distance between the constituents in the cluster increases only slightly before emergence, therefore most of the repulsion, if any, takes places outside the target. Such measurements can provide more detailed information on the physical state of the cluster when it emerges from the foil. The energy distributions of neutrals emerging at $0^{\circ}$ from carbon foils bombarded with $2.4 \mathrm{MeV} \mathrm{H}_{2}^{+}$beams (figure $6-\mathrm{b}, \mathrm{c}, \mathrm{d}_{-}$) 
exhibit a sharp central peak and two lateral peaks for the 1 and $3.3 \mu \mathrm{g} / \mathrm{cm}^{2}$ thick foils. This structure is not observable for the thicker targets. The energy separation between the two outside peaks corresponds to a liberated internal energy which is compatible with the formation at emergence of an unbound $\mathrm{H}_{2}^{+}$molecule in the $2 \mathrm{p} \sigma_{\mathrm{u}}$ state leading to the formation of a neutral atom in the ground state. Moreover the analysis of the widths of the angular distributions [18] confirms the role played by this repulsive state in the production of neutrals which emerge after capture of a target electron.

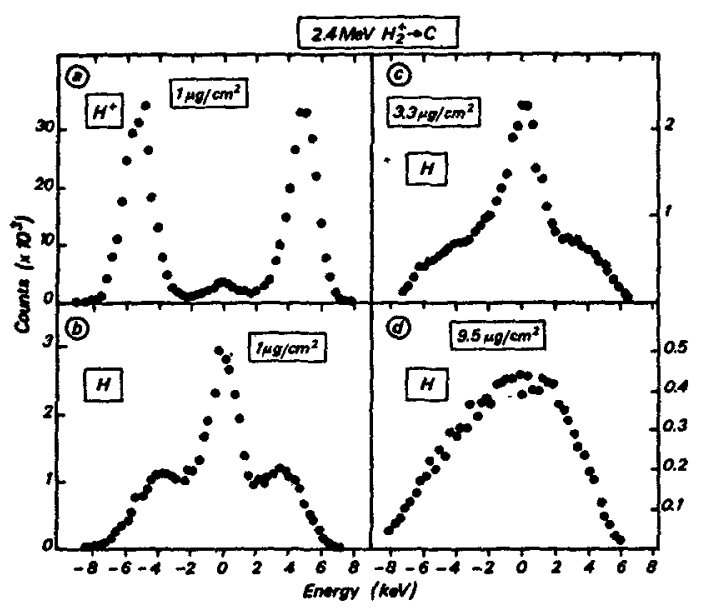

Figure 6

The central peak which dominates thinnest target spectra corresponds to neutrals which have experienced only a reduced repulsion. A central peak also dominates the angular distributions measured with the thinnest foils [18]. These neutrals can originate from two processes : either the $\mathrm{H}^{+}$ partner has been scattered by a target atom, or they separated gently from each other dowstream the foil. To decide between these two processes, one can examine the distribution of protons (figure 6 a) which exhibits also a small central peak between the two Coulomb explosion peaks. A joint analysis of proton and neutral energy distributions permits one to conclude that the first processes is mainly responsible for the central peak in the proton distribution. In contrast, the central peak in the neutral distributions corresponds to neutrals resulting from the dissociation of ${ }^{-} \mathrm{H}_{2}^{+}$molecules which emerge in the $1 \mathrm{~s} \sigma_{g}$ electronic ground state, but in a vibration-rotation state located in the continuum above the dissociation level. Thus the corresponding ion-solid interaction could be described as a vibrational dissociation of a $\mathrm{H}_{2}^{+}$molecule, a process which has been observed for a long time with gas targets.

$$
\text { Experimental results obtained with } \mathrm{H}_{3}^{+}
$$
projectiles confirm the existence of the two dissociation channels. Figure $7-\dot{b}, c, d-$ shows the energy spectra of neutral atoms emerging at $0^{\circ}$ from different foils. For the thickest foils where the neutrals are believed to arise from target electron capture, one observes mainly two peaks separated by $\sim 10 \mathrm{keV}$ due to the repulsive dissociation of the unstable $\mathrm{H}_{3}^{++}$molecule the into $\mathrm{H}-\mathrm{H}^{+}-\mathrm{H}^{+}$ fragments. Two new peaks appear with the thinner targets and dominate in the thinnest case.

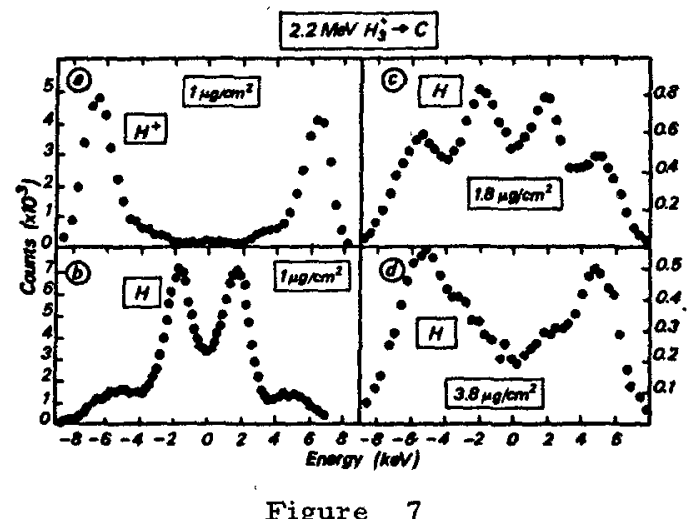

Their energy separation reveals a reduced repulsion from its two $\mathrm{H}^{+}$partners. We interpret the-. se two peaks as resulting from a two-step process: the emerging cluster behaves like a dicluster con-, sisting of a bare proton plus a $\mathrm{H}_{2}^{+}$molecule in the $1 \mathrm{~s} \sigma_{\mathrm{g}}$ continuum state. This repulsive $\mathrm{H}^{+}-\mathrm{H}_{2}^{+}$ system needs a few $10^{-15} \mathrm{sec}$. to liberate its kinetic energy. Simultaneously the $\mathrm{H}_{2}^{+}$molecuhe undergoes a vibrational dissociation which takes much more time and which transfers no additionnal energy to the resulting $\mathrm{H}-\mathrm{H}^{+}$pair. To test this model we have compared the reduced energy separation with the energy separation resulting from the $\mathrm{H}^{+}-\mathrm{H}_{2}^{+}$repulsion. For that we measured the 
energy distribution of the bound $\mathrm{H}_{2}^{+}$molecules emerging at $0^{\circ}$ from foils bombarded with $\mathrm{H}_{3}^{+}$ beams. The agreement is good enough to support the idea of the two-step process described here.

These observations suggest that transmitted electrons may occupy a molecular ground state at emergence as they did in the incident projectile and thus these electrons would be in a bound state inside the solid.

\section{MOLECULAR TRANSMISSION}

The experiments described above concer ned the formation of neutral atoms via different molecular states. Some years ago, bound $\mathrm{H}_{2}^{+}$molecular were discovered [20] among the particles transmitted through a carbon foil bombarded with a $\mathrm{H}_{2}^{+}$beam. Since, extensive studies of molecular yields with $\mathrm{H}_{2}^{+}$and $\mathrm{H}_{3}^{+}$beams in the $\mathrm{MeV}$ range through amorphous and crystal targets have been performed $[21]$. The analysis of the experimental data indicates that two parameters govern the trans mission of $\mathrm{H}_{2}^{+}$ions through amorphous foils : the cluster dwell-time which determines the mean interproton distance at emergence and the neutral fraction $\Phi_{0}$. For crystal targets, the channeling conditions increase strongly the molecular yield due to a reduced transverse repulsion which decreases the interproton separation at emergence.

Molecular yields have been investigated by Brandt et al. [22] with a variery of ion clus ters. The ordering of molecular yields has been interpreted by Brandt and Ritchie [ 8 ] in terms of wake interferences : the leading and the trailing ions in a dicluster oriented along their direction of motion could propagate together in a lock-step mechanism.

\section{MOLECULAR ION STRUCTURE}

A recent development in the study of dissociation of fast molecular ions in thin foils concerns the possibilities for obtaining molecular structure information. The first case studied is $\mathrm{H}_{3}^{+}$ions [23]. Theoretical considerations predicted two stable configurations, a triangular structure (having a higher binding energy) and a collinear structure. This investigations was initiated simultaneously at Argonne, Rehovoth and Lyon. The measurements at Lyon consisted of measuring the angular distributions of transmitted pairs of free protons belonging to the same ion cluster and emerging in the same direction from thin foils bombarded with $\mathrm{H}_{3}^{+}$projectiles. Figure 8 shows such an angular distribution of $\mathrm{H}^{+}-\mathrm{H}^{+}$ pairs exhibiting two peaks symmetrical around the beam axis. In order to emerge of axis a pair of protons has to be aligned with the beam axis inside the foil and has to suffer a transverse repulsion from the third proton of the same cluster. This is possible only for a triangular structure. Colinear projectiles would produce a central peak of $\mathrm{H}^{+}-\mathrm{H}^{+}-\mathrm{H}^{+}$events, which is not observed. From these distributions, one can also deduce the most probable interproton separation in the projectile.

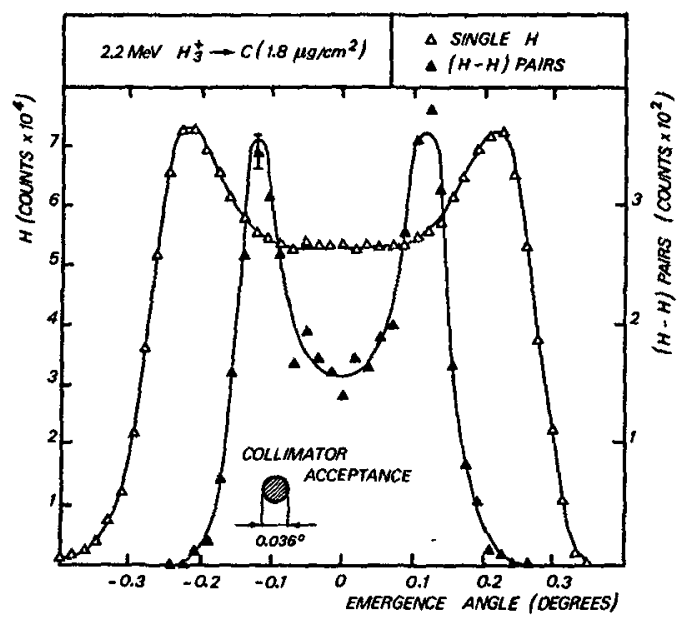

Figure 8

Since these experiments, Gemmell et al. [24] have reported measurements concerning $\mathrm{CO}_{2}^{+}$and $\mathrm{N}_{2} \mathrm{O}^{+}$molecular ions. From the energy spectra of the dissociation fragments emerging in the forward direction, they can infer that these two molecules are linear with structure $\mathrm{O}-\mathrm{C}-\mathrm{O}$ and $\mathrm{N}-\mathrm{N}-\mathrm{O}$. In addition, and as mentioned by the authors, the asymmetry in population of the peaks in the energy spectra of oxygen could be due to alignment resulting from wake effects. 


\section{CONCLUSION}

The study of the penetration of fast light ions and molecular ions through thin foils gives access to new fundamental aspects of the ion solid interaction. The hydrogenic beams are particularly convenient and interesting tools for such fundamental studies. In addition, the dissociation of fast molecular ions opens up new possibilities for the determination of molecular structure.

\section{BIBLIOGRAPHIE}

[ 1 ] D.S. Gemmell, J. Remillieux, J. C. Poizat, M. J. Gaillard, R. E. Holland and Z. Vager, Phys. Rev. Lett., 34, 1420, (1975) and Nucl. Instr. Meth., 132, 61, (1976)

[ 2 ] J. Remillieux, Proc. of 10th I.C.P.E.A.C. Paris, (1977)

[ 3 ] J. Golovchenko and E. Laegsgaard, Phys. Rev, , A-9, '1215, (1974)

[ 4 ] J. Neufeld and R.H. Ritchie, Phys. Rev., 98, 1632, (1955)

[ 5 ] V.N. Neelavathi and R.H. Ritchie, in Atomic Collisions in Solids, Plenum Press, New York, (1975)

V. N. Neelavathi, R.H. Ritchie and W. Brandt, Phys.Rev. Lett. , 33, 302, 670(E), (1974); 34, 560(E), (1975)

R.H. Ritchie, W. Brandt and P.M. Echenique, Phys. Rev., B-14, 4808, (1976)

[ 6 ] D.S. Gemmell, P.J. Cooney, W.J. Pietsch, A. J. Ratkowski, Z. Vager and B. J. Zabransky, 7th Int. Conf. on At omic Collisions in Solids, Moscow, (1977)

[ 7 ] K. Dettmann, K. G. Harrison and M.W. Lucas J. of Phys. B, 7,269 , (1974)

[ 8 ] W. Brandt, A. Ratkowski and R. H. Ritchie, Phys. Rev. Lett., 33, 1325, (1974)

W. Brandt and R.F. Ritchie, Nucl. Instr. Meth., 132, 43, (1976)

L] J.W. Tape, W.M. Gibson, J. Remillieux, R. Laubert, and H. E. Wegner, Nucl. Instr. Meth., 132, 75, (1976)

[ 10] N.R. Arista, Phys. Rev., B-18, 1, (1978)

[ 11] R.A. Mc Corkle and G. J. Iafrate, Phys. Rev. Lett., 39, 1263, (1977)

[ 12] H. G. Berry, A.E. Livingston and G. Gabrielse, Phys. Lett. , 64 A, 68,(1977)

[ 13] F.K. Chen, R. Laubert and W. Brandt, Phys. Rev., A 15, 2227, (1977)
[ 14] A. Lurio, H.H. Andersen and L.C. Féldman, Phys. Rev. A 17, 90, (1978)

[ 15$]$ S. Datz, F.W. Martin, C.D. Moak, B.R. Appleton and L. B. Bridwell, Rad. Effects, 12, 163, (1972)

[ 16 ] M.J. Gaillard, J.C. Poizat, A. Ratkowski, J. Remillieux and M. Auzas, Phys. Rev., A 16, 2323, (1977)

[ 17] M.C. Cross, Phys. Rev., B 15; 602, (1977)

[ 18 ] M.J. Gaillard, J.C. Poizat and J. Remillieux, Phys. Rev. Lett., 41, 159, (1978)

[ 19] B.T. Meggitt, K. G. Harrison and M. W. Lucas, J. of Phys. B, 6, L, -362 , (1973)

[ 20] J.C. Poizat and J. Remillieux, Phys. Lett. , $34 \mathrm{~A}, 53,(1971)$

[ 21] M.J. Gaillard, J.C. Poizat, A. Ratkowski, and J. Remillieux, Nucl. Instr. Meth., 132, 69, (1976)

M. J. Gaillard, J.C. Poizat and J. Remillieux, in Atomic Collisions in Solids, Plenum Press, New York, (1975)

[ 22$]$ W. Brandt, R. Laubert and A. Ratkowski, Nucl. Instr. Meth., 132, 57, (1976)

[ 23 ] M.J. Gaillard, D.S. Gemmell, G. Goldring, J. Levine, W.J. Pietsch, J. C. Poizat, A. Ratkowski, J. Remillieux, Z. Vager and M.J. Zabransky, Phys, Rev., $\underline{A-17}$, 1797, (1978)

[ 24 ] D.S. Gemmell, E. P. Kanter and W.J. Pietsch, Chem. Phys. Lett., 55, 3.31, (1978) 